\title{
Research on Emergency Strategy of Green Agricultural Product Supply Chain*
}

\author{
Xuezhu Cao \\ School of Safety Science and Emergency Management \\ Wuhan University of Technology \\ Wuhan, China
}

\begin{abstract}
In recent years, people have gradually increased the quality requirements for green food. However, there have been frequent incidents in this field and the public and enterprises have suffered huge losses. This paper analyzes the causes of emergencies from the perspective of green supply chain, for example, the external environment is uncertain, lack of emergency mechanism, traceability and supervision system is imperfect, information disclosure is unreasonable and prediction errors, etc. On the basis of analyzing the characteristics of causes and emergencies, it puts forward countermeasures, such as establishing a sound supply chain emergency mechanism, combining traceability with the supervision system, improving the information disclosure system, and constructing cooperation contracts.
\end{abstract} chain

Keywords—green agricultural products; emergencies; supply

\section{INTRODUCTION}

In recent years, people's requirements for food quality have gradually increased. However, there are frequent incidents in this field and the damage is serious. "Fake eggs", "Sudan red" and "Hainan poison bananas" have become hot spots of social concern.

Domestic scholars have studied the emergencies of agricultural products from the classification, causes, effects and hazards of emergencies. $\mathrm{Zi}$ Bowen designed the reorganization of the green supply chain of agricultural products driven by factors such as consumer demand, green barriers, policy regulation, information technology, and winwin basis, and proposed management strategies [1]. On the basis of analyzing the operational flow of green supply chain of agricultural products, Xiao Liang proposed five levels of information system, logistics system and organization mode of agricultural product circulation to ensure the effective operation of supply chain circulation mode [2]. Wang Yong, You Zeyu built an indicator system from six aspects of business cost, operation status, production quality, customer service, green environmental protection and financial value, and used the analytic hierarchy process to evaluate the green supply chain of "food network" [3]. Wang Puqing and Zhou Deyi et al. pointed out that the higher the integration degree of agricultural product supply chain, the higher the quality and safety level of products provided [4].
Through the analysis of the above documents, it found that the research on agricultural products emergencies is still in its infancy, and there is no research on emergency response from the perspective of agricultural product supply chain. Therefore, this paper analyzes the causes of the emergent events in the green supply chain of agricultura products in recent years. On this basis, the strategy of green supply chain to deal with emergencies proposed, which fills the blank of this research

\section{RELEVANT THEORY OF EMERGENCIES IN GREEN AGRICULTURAL SUPPLY CHAIN}

\section{A. Characteristics of Green Agricultural Product Supply Chain}

There are many links in the green agricultural product supply chain and the structure is complex. Green agricultural production enterprises pursue maximum scale benefits. The inventory and distribution of green agricultural products constitutes the majority of the costs management of green agricultural product supply chain, therefore, the green agricultural product supply chain presents some characteristics different from other industries. Firstly, the green agricultural supply chain has strict quality requirements. The consequences and adverse effects of problems with green agricultural products often didn't eliminated in a short period, and some even cause the supply chain of such green agricultural products to collapse, which requires the supply chain to carry out strict quality control from the selection of raw materials, to transportation, to processing. Refrigerated storage and transportation of perishable raw materials, semi-finished products and finished products is necessary. Secondly, the green agricultural supply chain needs to respond quickly to customer needs. Consumers are increasingly expecting green produce, hoping to get products that are safe, health-care, and specially packaged, which shortens the life cycle of products and requires the development of new products or new flavors. Thirdly, the green agricultural supply chain must establish an agile downstream distribution network. Companies continue to increase revenue through multi-faceted distribution networks such as supermarkets, wholesale, chain stores, and convenience stores, thereby further reducing costs. 
In short, green agricultural products are typical mass consumer goods, which constantly change with the consumption structure, consumption level and consumption habits of consumers. Factors such as the quality assurance, consumption structure, consumption trends and periodicity of green agricultural products, and the length of the green agricultural product supply chain have decided that green agricultural product supply chain need to meet the changing needs of end consumers quickly. As a result, the supply chain faces challenges such as more market segmentation, faster response, continuous value chain shifts downstream, and more accurate consumer demand.

\section{B. Related Theory of Supply Chain Emergencies}

China's "Overall Emergency Response Plan for Public Emergencies" (January 8, 2006) and the "Emergency Response Law" (November 1, 2007), which are considered to be sudden, are extremely likely events and disasters that cause serious harm or negative impact on society and urgent intervention by unconventional means. Incidents characterized by suddenness, destructiveness, complexity, two-sidedness, and controllability.

The occurrence of emergencies can easily cause problems such as fluctuations in demand, out of control of prices, sharp increase in costs, misalignment or even breakage of supply chains. All of the above factors will inhibit the maximization of the benefits of the supply chain system. It has caused problems in the coordination of supply chain in different industries. Once the survival and development of member companies in the supply chain have been in crisis, it will cause incalculable losses to society. Strengthening the supply chain to deal with emergencies has become a hot issue.

From the point of view of the chain of operations in the supply chain, emergencies can divided into the following three categories. First is the supply chain. In the upstream of the supply chain, due to the shortage of raw materials faced by manufacturers, production equipment failures, lack of production labor, etc., the products can't be produced and supplied in time, which will result in the entire supply chain not functioning properly to meet the needs of the end market. Second is the operation link. In the operation process of the supply chain, due to various management negligence or sudden policy interference, it will also pose a threat to the supply chain. At the same time, due to the breach of contract and non-integrity of the members of the supply chain, it will also disrupt the coordination of the entire supply chain and cause losses for all members. Finally is the demand link. Due to natural, social or economic problems, market demand may undergo sudden changes, and the demand for a certain product will fluctuate greatly, causing supply chain companies quickly respond to the sudden change in demand to ensure that the overall interests are not damage.

Existing research shows that when the external environment is determined, the supply chain is easy to achieve coordination. If the external environment of the supply chain changes from deterministic to uncertain, the supply chain will turn from coordination to imbalance. The current external environment of the supply chain is becoming more and more complex, and supply chain management tends to be globalized, informative, and lean. Leaning improves the operational efficiency of the enterprise but reduces the flexibility of the supply chain, making the supply chain system quite fragile. The complex external environment contains a variety of uncertainties, which makes the probability of sudden outbreaks increase significantly, and the fragile supply chain is highly vulnerable to sudden attacks and becomes dysfunctional or even interrupted.

\section{CAUSES OF EMERGENCIES IN THE GREEN AGRICULTURAL SUPPLY CHAIN}

Incidents often take the lead, and emergencies that occur at a certain point may lead to the collapse of the entire supply chain. In the face of emergencies, many companies have to deal with the lack of surgery. The reasons for this are often the following:

\section{A. Uncertainty of the External Environment}

The external environment is a macro environment, including natural disasters, policies and regulations, and social security. The external environment is the big environment in which all things in the universe exist, and the disturbance of the external environment will have an impact on any existing individuals. For the fragile supply chain, the main influencing factors are the interference from the external environment. The environmental changes are unpredictable and complex, which makes the recovery process of the supply chain more complicated. As the complexity of external environmental factors increases, the time required for supply chain recovery will also increase.

\section{B. The Traceability and Supervision System Is Not Perfect}

Due to the imperfect traceability system, enterprises cannot keep abreast of the root causes of emergencies, and even think that the emergencies that have occurred have nothing to do with them. The node companies in the supply chain of raw material supply enterprises, production enterprises and retail enterprises push each other's responsibilities, rather than cooperate with each other to find the source of emergencies. Government supervision and implementation are not in place and are not timely.

\section{The Information Released Is Not Active and Not Timely}

The information released by the relevant units is not active and not timely. If food relate to people's lives closely, after food-related emergencies, people will learn about relevant information through various channels soon. If companies haven't proactively, timely, and accurately published information, various rumors will emerge, causing greater panic and expanding the negative impact of emergencies.

\section{There Are Loopholes in the Supply Chain}

The supply chain is a nonlinear hybrid system lacking a stable foundation. The dependence of each member company is strong, which makes the supply chain extremely fragile. 
Small fluctuations in any link transmitted to the entire supply chain, which ultimately leads to unstable operation of the supply chain. Incidents are unpredictable, but if there are defects or loopholes in the supply chain, the occurrence of an emergency is inevitable, but the time and form of occurrence are accidental. Therefore, the loopholes in supply chain management have become hidden obstacles that lead to its unstable operation, such as illegal operation, equipment failure, and information distortion.

\section{E. Prediction Errors}

Forecasts include forecasts of demand, forecasts of decisions, forecasts of production, and predictions of emergencies. The supply chain system is uncertain, and the prediction of any link may be inaccurate. If the forecast is far from the actual situation, and the supply chain can't bear it, it will be damaged or even broken.

\section{F. Lack of Effective Emergency Response Mechanisms}

Supply chain node enterprises lack a sound emergency mechanism, and can't find hidden disasters in time. The failure to investigate potential risks will lead to supply chain emergencies. After the emergency occurred, emergency management measures couldn't be taken in time, resulting in an expansion of the supply chain impact. Lack of emergency management can lead to a series of lags, including reaction lag, control lag, and processing lag. In the event of an emergency, the company does not have a set of effective emergency plans and promptly responds. For example, many companies tend to expose their companies to embarrassing situations as the media exposes them, and then try to eliminate the impact of emergencies.

\section{STRATEGIES FOR RESPONDING TO EMERGENCIES IN THE GREEN AGRICULTURAL SUPPLY CHAIN}

Simplifying the complexity of the supply chain during the construction phase of the supply chain is a feasible method. Under the influence of the incident, an excessive complex supply chain will hinder its corresponding speed. For that cause, the core enterprises of the supply chain can reduce the complexity of the supply chain by reducing the length and hierarchy of the supply chain and appropriately reducing the diversity of the supply chain products.

It is necessary for enterprises to strengthen its market position. Through the strengthening of the production and sales activities of the products, the core enterprises in the supply chain can enhance their market competitiveness and thus consolidate their market position. In this way, it can create market monopoly conditions for member companies of supply chain, thereby ensuring their fixed consumer demand, avoiding large fluctuations in their market demand, and causing losses to the supply chain enterprises.

Improving the internal information system of the supply chain is another effective method. Members of the supply chain should strengthen internal information sharing based on the coordination mechanism, so that member companies can jointly carry out activities such as demand forecasting and inventory management to ensure the smooth completion of their daily management activities. It makes the internal information communication in the supply chain under the emergency smoother and enhances the timeliness of emergency activities.

\section{A. Establishing a Sound Supply Chain Emergency Response Mechanism}

It is essential to establish a sound emergency response mechanism. In order to reduce the negative impact of emergencies on the supply chain, the emergency response plan for the agricultural product supply chain should refer to the national emergency plan for major food safety incidents. In addition, pay attention to the following points when formulating emergency plans for agricultural product supply chains:

1) Supply emergency measures: In order to avoid the shortage of supply, the core enterprises can adopt the strategy of multi-source suppliers to share the supply risks, and avoid the great impact that the supply shortage of raw materials of one supplier may bring. With a multi-source vendor strategy, supply chain core companies can reduce the sudden loss of events that a single supplier can bring.

2) Demand emergency measures: In order to respond to the sudden situation of market demand, enterprises should make preliminary predictions on market demand, and arrange production and sales activities according to their own production capacity. At the same time, each member of the supply chain needs to establish a sound information system, track the fluctuations of market demand in real time, and provide timely feedback on product sales to ensure timely response to changes in market demand.

3) Operational emergency measures: The agricultural product supply chain should strengthen coordination in its operation process to reduce the adverse effects caused by unexpected situations. In the operation process of the supply chain, it is necessary to establish a sound and timely information system to realize the timely sharing of information between enterprises and farmers, so that members can share product supply and demand information, and jointly manage inventory to avoid information asymmetry.

\section{B. Combining Traceability and Supervision}

Establishing a traceability system is important. The traceability system should set reasonable information range and traceable distance, and control the traceability cost reasonably by weighing the cost and benefit. Once an emergency occurs, the food flow tracked according to the information recorded in each link from the raw material production to the final consumption of the finished product. For the unconsumed and harmful food, it should be recycled as soon as possible, and the company punished as soon as possible. The dereliction of duty and dereliction of duty in the handling of security emergencies punished accordingly. At the same time, the management of farmers strengthened, and the awareness of risk prevention improved through 
publicity and education training for farmers, transportation enterprises and sales enterprises in the supply chain.

\section{Improving the Information Disclosure System}

- It is necessary to do a good job of information disclosure.

After security emergencies, the government must play a leading role, not only to be accountable to the public, to protect consumer rights, but also to safeguard the legitimate rights and interests of enterprises in the supply chain, such as farmers, suppliers and distributors, to avoid the expansion of the situation causing greater losses. Therefore, the government should disclose information in a timely and accurate manner, do a good job in guiding public opinion, do a good job in information collection, reporting and notification, and ensure that people receive information in a timely manner.

\section{Building a Cooperation Contract}

Retail investors operate most of the fresh agricultural products in China independently. Due to the low level of funds and poor access to information, they are often unable to cope with emergencies. Therefore, building a cooperation contract is a good way. First, farmers and farmers can unite to increase the scale while improving bargaining power. Second, farmers can establish long-term cooperative relationships with wholesalers and retailers, realize effective product docking, reduce transaction costs, and combine the above-mentioned traceability system to achieve quick response.

\section{CONCLUSION}

Methods to improve the ability of the fresh agricultural product supply chain to resist emergencies includes the following aspects, for example, it is necessary for the nodes in the supply chain to unite with each other, establish strategic partnerships, and quickly obtain complementary resources and capabilities by sharing information and resources, effectively reducing or dispersing Risk of incidents. Based on the theoretical summary of supply chain emergencies, this paper analyzes the characteristics of food supply chain, combines supply chain management theory to propose ways to improve the emergency response capability of emergencies in the process of supply chain management from different levels and provide a corresponding reference for the management. The issues about how to design effective contracts and how to quantify supply chain emergency risks will become the next research direction.

\section{REFERENCES}

[1] Tan Dan and Zhu Yulin, "The Implement Patterns of Green Supply Chain of Agricultural on Synergetic Theory," On Economic Problems, vol. 1, pp. 88-90, 2011.

[2] Xiao Liang, "Agricultural Product Green Supply Chain Circulation Pattern and Operation Flow Research," Journal of Technical Economics \& Management, vol. 11, pp. 109-112, 2011
[3] Wang Yong and You Zeyu, "Establishment of Performance Evaluation Model for Green Supply Chain of Internet of Vegetables," Logistics Technology, vol32, pp. 227-230, 2013.

[4] Wang Puqing, Zhou Deyi and Lv Zhixuan, "Food Safety and Organizational Modes of Agricultural Products' Supply Chain," Issues in Agricultural Economy, vol. 3, pp. 8-12, 2009. 